\title{
Seroprevalence and trends in transfusion transmissible infections among voluntary non-remunerated blood donors at the Malawi Blood Transfusion Service-a time trend study
}

\author{
Bridon M'baya ${ }^{1}$, Vincent Jumbe ${ }^{2}$, Vincent Samuel ${ }^{3}$, \\ Robert M'bwana ${ }^{1}$, Charles Mangani ${ }^{4}$
}

1. Malawi Blood Transfusion Service,

2. College of Medicine, Department of Health Systems and Policy

3. College of Medicine, Research Support Centre

4. College of Medicine, Department of Public Health

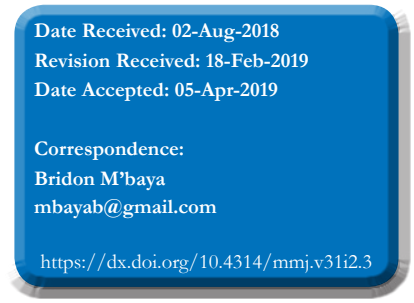

\section{Introduction}

Abstract

Collecting blood from voluntary non-remunerated blood donors from low risk populations is a key strategy for blood safety. Identifying such populations involves analysis of population and blood donor data to identify risk factors for transfusion transmissible infections (T'TIs). There are no recent seroprevalence statistics for blood donors in Malawi. This study fills this gap by describing characteristics of blood donors, trend of annual prevalence of HIV, HBV, HCV and syphilis and factors associated with each TTI.

Methods

Retrospective analysis of blood donors' records in the MBTS database from 2011 to 2015 was undertaken. Summary statistics were performed to describe characteristics of the blood donors. Univariable and multivariable logistic regression analyses were performed to determine association between prevalence of infections and socio-demographic factors. Time trend analysis was done to assess changes in prevalence. P-value $<0.05$ was considered statistically significant.

Results

The number of blood donors screened over the 5 year period was 125,893 . The mean number of donors donating blood per year was 39, 289; median age was 19 years; $82 \%$ were male, $87 \%$ single and $72 \%$ students and $56 \%$ were repeat blood donors. Overall prevalence of each TTI decreased. The 2015 prevalence was: $3.6 \%$ for HBV; $1.9 \%$ for HIV; $2.6 \%$ for Syphilis and $1.0 \%$ for HCV while the 2011 prevalence was $4.7 \%$ for HBV; $3.5 \%$ for HIV $3.2 \%$ for syphilis and $2.4 \%$ for HCV.

Repeat blood donors had significantly lower prevalence of TTIs than first time donors. Females were associated with lower risk for HBV, HCV and syphilis. Age $\geq 25$ years and being out of school were associated with HIV. Age $\geq 25$ years was associated with reduced risk for $\mathrm{HCV}$ and being self-employed and married were each associated with syphilis.

Conclusion

The typical blood donor is a young single male student. Repeat blood donation improves safety of the blood supply.

\section{Key Words}

Transfusion transmissible infections (T'TIS), voluntary non remunerated blood donors (VNRBDs), HIV, Hepatitis B (HBV), Hepatitis C (HCV), Syphilis, family replacement blood donors (FRBDs)

\section{Introduction}

The World Health Organisation's (WHO) integrated strategy for blood safety has 4 key components one of which is collecting blood only from voluntary non-remunerated blood donors (VNRBDs) from low risk population groups ${ }^{1}$. Identifying low risk population groups involves analysing general population and blood donor specific data to identify possible risk factors for transfusion transmissible infections (T'TIs). When establishing the national blood donation criteria at the start of its operations in 2004, the Malawi Blood Transfusion Service (MBTS) relied on international recommendations and local general population based data ${ }^{1}$ 2. There was no national data on any type of blood donors. The available published TTI prevalence reports on blood donors in Malawi were only for family replacement blood donors. ${ }^{4-7,8-10}$ These reports were either based on incomplete program data ${ }^{4-7}$ or old studies dating back 12-18 years ${ }^{8-10}$ with no recent seroprevalence reports for voluntary nonremunerated blood donors.
The WHO recommendation to collect blood only from voluntary non-remunerated blood donors was based on their lower prevalence of TTIs when compared with family replacement blood donors and paid blood donors ${ }^{11}$. Voluntary non-remunerated blood donors are a self-selected sub-population that is different to the general population. To improve the safety of the national blood supply, it is also important to analyse blood donor specific data in this subpopulation in order to identify patterns that are specific to this population ${ }^{12-13}$. This study, therefore, provides, for the first time in Malawi, information on the prevalence and trend of prevalence of transfusion transmissible infections (T'TIs) and socio-demographic factors associated with positivity for TTIs among voluntary non-remunerated blood donors.

\section{Methods}

\section{Study design, setting and study subjects}

A retrospective descriptive study of blood donor data recorded in the electronic database at the Malawi Blood 
Transfusion Service (MBTS) in Blantyre was performed in 2016. This database contains information routinely collected from all blood donors who donate blood at the MBTS from 27 of the 28 districts in Malawi. The MBTS does not collect blood from Likoma district for logistical reasons as this district is only reachable by unreliable water transport. The study population was voluntary non-remunerated blood donors (VNRBDs) who donated blood at the MBTS in the 5 year period from January 2011 to December 2015. The MBTS implements two levels of screening of blood donors: pre-donation and post-donation screening. Pre-donation screening also has two stages which are: educating blood donors on the eligibility criteria for blood donation which aims at encouraging self-deferral among potential blood donors and administering a blood donation questionnaire which contains the national blood donation acceptability criteria. This helps screen out those who are not eligible to donate blood. The exclusion criteria for blood donation is extensive. It includes, among others, those who are unwell or feel unhealthy; those who engage in behaviour deemed at risk for transfusion transmissible infections (TTIs) such as tattooing and multiple sexual partners; age below 16 or above 65 years; past medical history suggestive of HIV, hepatitis or syphilis; past or present history of renal, cardiovascular, central nervous system and metabolic disorders such as insulin dependent diabetes; haemoglobin below $12.5 \mathrm{~g} / \mathrm{dl}$ and weight below $42 \mathrm{kgs}$. Only individuals who satisfy the national blood donation acceptability criteria are accepted as blood donors and hence are allowed to donate blood. Records of these individuals are kept in the electronic MBTS database. The second phase of screening involves postdonation laboratory testing of the donated blood for HIV, hepatitis $\mathrm{B}$ virus (HBV), hepatitis $\mathrm{C}$ virus $(\mathrm{HCV})$, syphilis and malaria parasites.

\section{Sample size}

Using the Taro Yamane method for sample size calculation for a finite population [formula:, a 95\% confidence interval, a type one error of $5 \%$, and an estimated population of 150,000 blood donors, the sample size was estimated to be 399. However, all blood donors in the MBTS data base during the study period of January 2011 to December 2015 were included in the study. This approach was taken because the MBTS stores blood donor information in an electronic database that could easily be retrieved without taking too much time. Because of this approach, the study population for each of the 5 years from 2011 to 2015 ranged from 37,111 to 41,728 .

\section{Data collection and management}

The following information was retrieved from the MBTS database and extracted into an Excel database: blood donor serology test results, age, sex, marital status, place of donation, occupation and number of donations. The various entries for occupation in the database were grouped into 4 categories that were used for analysis as follows: student, business/self-employed, employed (for those in formal employment) and 'others' to include the unemployed and all other occupation categories that did not easily fit into the first 3 categories. Places of donation were also organized from the individual names of villages, schools, workplaces and places of worship to districts thereby ending up with 27 places of donation. These 27 places were then grouped into 3 regions of Northern, Central and Southern regions of Malawi. Marital status was categorised into single, married, divorced/separated and widowed.

In line with the global pledge 25 blood donor retention strategy and the 16-25 year age-group of enrolment into the Malawi Club 25, age was also analysed as a binary variable as follows: those aged $\leq 25$ years and $>25$ years $^{14}$. Number of blood donations was also dichotomized to first time blood donors being those with 1 or less blood donations and repeat blood donors being those with more than 1 blood donation. The blood donor test results were limited to those for HIV, HBV, HCV and syphilis. The MBTS participates in an external quality assessment (EQA) program for all these tests. It does not participate in an EQA program for malaria parasite testing. This is why blood donor test results for malaria parasite testing were left out of this study.

\section{Laboratory screening}

For the blood test results, all tests were performed according to the manufacturer's instructions and validated standard operating procedures. The assays and algorithms used to determine a positive result were as follows:

\section{HIV serology}

Green screen ULTRA HIV antigen-antibody reagents (Bio-Rad, France) were utilised using the Evolis semiautomated platform. These were fourth generation enzyme immunoassays (EIA) that detect antibodies to HIV-I (groups $\mathrm{M}$ and $\mathrm{O}$ ) and HIV-II as well as the HIV p24 antigen. The algorithm involved repeating in duplicate all initial positives and interpreting results based on concordant two of the three. From August 2015, supplementary testing with Determine antibody rapid test kits (Allere, Japan) was added for those found positive with the EIA algorithm. Before 2015, in the database there were just two results categories: positive and negative. However, since 2015 a third category of discordant was added being those who test positive on EIA and negative on rapid test kit.

\section{HBV serology}

Monalisa HBsAg ULTRA reagents, (Bio-Rad, France) on the Evolis semi-automated platform were used. These were fourth generation EIA reagents that detect the HBV surface antigen ( $\mathrm{HBsAg}$ ). The algorithm involved repeating in duplicate all initial positives and interpreting results based on concordant two of the three.

\section{HCV serology}

Monalisa anti-HCV PLUS version3 reagents, (Bio-Rad, France) on the Evolis semi-automated platform were used. These were third generation EIA reagents which detect antibodies to the NS3 and NS4 regions of the capsid of the hepatitis $\mathrm{C}$ virus. The algorithm involved repeating in duplicate all initial positives and interpreting results based on concordant two of the three.

\section{Syphilis serology}

Manual Treponema Pallidum Haemaglutination Assay (TPHA) reagents (Bio-Rad, France) using micro plates were used. These detect IgG antibodies to Treponema pallidum. The algorithm involved repeating in duplicate all initial positives and interpreting results based on concordant two of the three.

\section{Statistical analysis}

Data was cleaned, recoded and analyzed using Stata for Windows version 12. Summary statistics from the number of individual blood donors in the MBTS database per year https://dx.doi.org/10.4314/mmj.v31i2.3 
for each of this 5 year period were calculated. Annual prevalence was calculated and expressed in percentages per year for each infection for all blood donors and separately for first time blood donors and for repeat blood donors. These were used to plot graphs to illustrate the 5 year trend of annual prevalence. The Cochran-Armitage Test for trend of proportions was used to test the statistical significance of the observed trends.

To determine the relationship between a positive TTI result with age, sex, marital status, occupation and number of donations, univariable and multivariable logistic regression analyses were performed using the latest (2015) group of blood donors. to evaluate the relationship.. Although all blood donors who donated blood in 2015 were used in the analysis, they were still a sample of all blood donors. As such $95 \%$ confidence intervals $(\mathrm{CI})$ were calculated for the odds ratios (OR) and the adjusted odds ratios (AOR). For all statistical tests, the level of significance was evaluated at 0.05 .

\section{Missing data}

One of the main challenges with using secondary data is that some needed data maybe missing and some data may be incorrectly captured into the database. For this study, missing data for summary statistics was below $2 \%$ for all parameters and missing data for calculating prevalence ranged from $2.3 \%$ in 2011 to $17.5 \%$ in 2015. Missing data mainly constituted those blood donors whose blood test results were absent from the database for that particular year. This was caused by failure of laboratory personnel to manually enter into the database all blood test results. The missing data was random and non-differential and did not each exceed $20 \%$. As such missing data did not affect the results of this study.

\section{Ethical considerations}

To ensure donor confidentiality, data was anonymised with all personal identifiers removed.

New numbers were allocated to the study participants that could not be linked to the blood donors. The process of delinking donor identities was undertaken exclusively by a data manager from Malawi Blood Transfusion Service (MBTS). All records were kept in a secure area.

Only secondary data which had been generated using procedures pre-consented to by the blood donors themselves was used hence no fresh consent was sought from the blood donors. Permission to carry out the research was granted by the MBTS and ethical approval was obtained from the College of Medicine Research and Ethics Committee (COMREC).

\section{Results}

\section{Socio-demographic characteristics of the study population}

A total of 125,893 different individuals donated blood to the MBTS over the period from January 2011 to December 2015. Some of them donated blood more than once in each year. On average 39, 289 people donated blood to the MBTS per year of whom $44.7 \%$ donated blood in the southern region; $38.3 \%$ in the central region and $17.0 \%$ in the northern region. The blood donors were generally young with median age of 19 years (interquartile range 17-24 years), $79.8 \%$ of the blood donors were aged 25 years and below; $82.0 \%$ were male, $18.0 \%$ female; $87 \%$ were single, $12 \%$ married, $0.3 \%$ divorced and $0.1 \%$ widowed. Most of the blood donors(72.1\%) were students, $14.4 \%$ employed, $6.4 \%$ self-employed, $6.5 \%$ were in the other employment category. The proportion of first time blood donors was $44.0 \%$ with $56.0 \%$ being repeat blood donors.

\section{Annual prevalence of TTIs in blood donors}

In 2015, the overall positivity rates of HBV, syphilis, HIV and $\mathrm{HCV}$ were $3.6 \%, 2.6 \%, 1.9 \%$, and $1.0 \%$, respectively (Table 1). Prevalence of each TTI was higher in first time blood donors compared to repeat blood donors. The annual prevalence of each infection in all blood donors was lower in the northern region when compared with the other 2 regions (Table 1).

Table 1 Prevalence of infections in blood donors in 2015

\begin{tabular}{|c|c|c|c|c|c|c|c|c|}
\hline & \multicolumn{2}{|c|}{ HIV $(\%)$} & \multicolumn{2}{|c|}{ HBV $(\%)$} & \multicolumn{2}{|c|}{ HCV (\%) } & \multicolumn{2}{|c|}{ Syphilis (\%) } \\
\hline & Prev & $95 \% \mathrm{Cl}$ & Prev & $95 \% \mathrm{Cl}$ & Prev & $95 \% \mathrm{Cl}$ & Prev & $95 \% \mathrm{Cl}$ \\
\hline \begin{tabular}{|l|} 
First time \\
blood donors \\
(n= 15,560)
\end{tabular} & 2.8 & $2.6-3.1$ & 5.1 & 4.8-5.5 & 1.2 & $1.0-1.3$ & 3.3 & $3.1-3.6$ \\
\hline $\begin{array}{l}\text { Repeat } \\
\text { blood donors } \\
(n=18,877)\end{array}$ & 1.2 & 1.1-1-1.4 & 2.3 & 2.1-2.5 & 0.9 & $0.8-1.0$ & 2.1 & $2.0-2.3$ \\
\hline $\begin{array}{l}\text { All blood } \\
\text { donors } \\
(\%) \\
(n=34,437)\end{array}$ & 1.9 & $1.8-2.1$ & 3.6 & 3.4.-3.8 & 1.0 & $0.9-1.1$ & 2.6 & $2.5-2.8$ \\
\hline
\end{tabular}

Prevalence according to place of donation amongst all blood donors

\begin{tabular}{|l|l|l|l|l|l|l|l|l|}
\hline $\begin{array}{l}\text { Northern } \\
\text { region } \\
\text { (n=5,562) }\end{array}$ & 1.1 & $0.9-1.3$ & 2.6 & $2.2-3.0$ & 0.9 & $0.7-1.1$ & 1.8 & $1.5-2.1$ \\
\hline $\begin{array}{l}\text { Central } \\
\text { region } \\
(n=13,211\end{array}$ & 2.7 & $2.4-3.1$ & 3.9 & $3.5-4.3$ & 1.0 & $0.8-1.2$ & 3.4 & $3.0-3.7$ \\
\hline $\begin{array}{l}\text { Southern } \\
\text { region } \\
(n=15,364)\end{array}$ & 1.9 & $1.7-2.1$ & 3.8 & $3.5-4.1$ & 1.1 & $1.0-1.3$ & 2.6 & $2.4-2.9$ \\
\hline
\end{tabular}

\section{Trend of prevalence of TTIs in all blood donors}

The most prevalent T'TI over this 5 year period was hepatitis B while hepatitis C had the lowest prevalence (Figure 1).

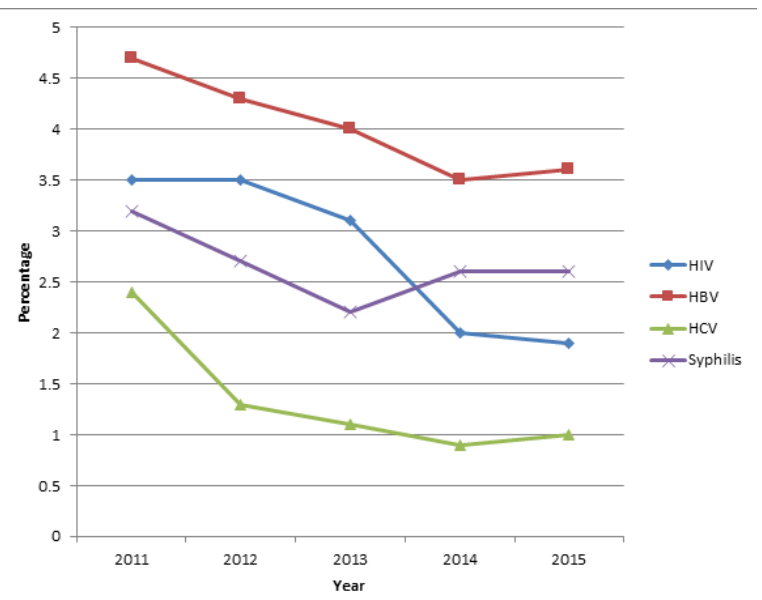

Figure 1 Trend of prevalence of transfusion transmissible infections in all blood donors

Across the 5 year period, HIV prevalence was higher than syphilis from 2011 to 2013 afterwards syphilis prevalence https://dx.doi.org/10.4314/mmj.v31i2.3 




Figure 2 Trend of prevalence of transfusion transmissible infections in first time blood donors

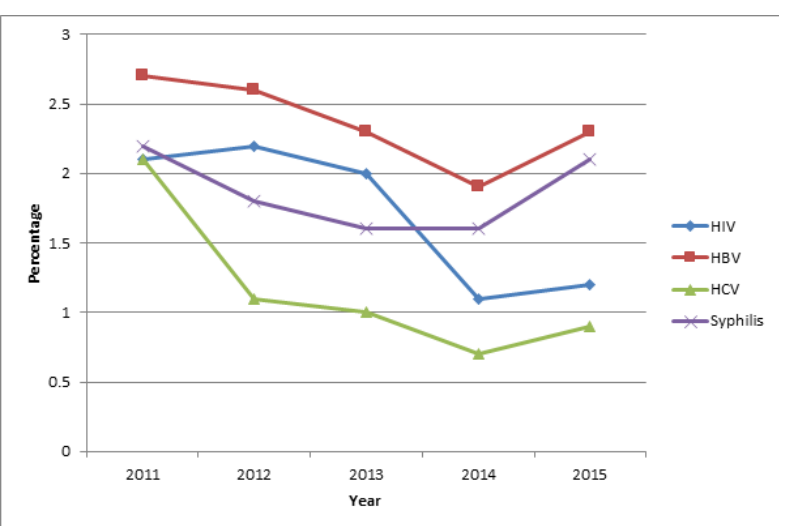

Figure 3 Trend of prevalence of transfusion transmissible infections in repeat blood donors

became higher. Overall, the general trend was that prevalence of infections went down between 2011 and 2015. This finding was statistically significant with a p-value of $<0.001$ for each infection (Cochran-Armitage Test for trend of proportions). The 2015 prevalence was: 3.6\% $(1,239 / 34,437)$ for $\mathrm{HBV}$; $1.9 \%(655 / 34,437)$ for HIV; $2.6 \%(896 / 34,437)$ for Syphilis and 1.0\% $(343 / 34,437)$ for $\mathrm{HCV}$ while the 2011 prevalence was 4.7\% $(1,744 / 36,961)$ for $\mathrm{HBV} ; 3.5 \%$ $(1,283 / 36,961)$; for HIV 3.2\% $(1,200 / 36,961)$ for Syphilis and $2.4 \%(904 / 36,961)$ for HCV.

Table 2: Factors associated with HIV

Variable

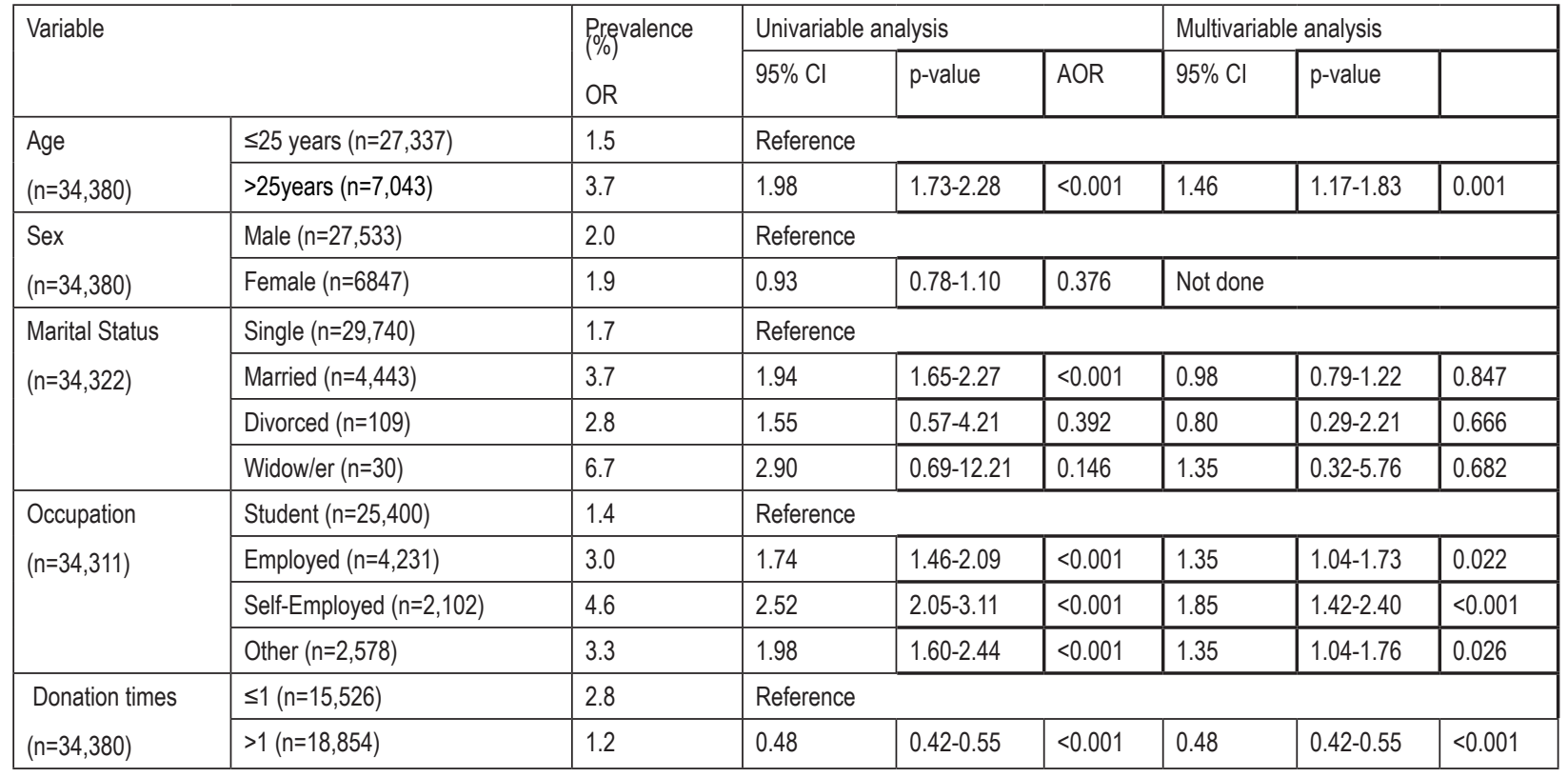




\section{Table 3: Factors associated with hepatitis B}

\begin{tabular}{|c|c|c|c|c|c|c|c|c|}
\hline \multicolumn{2}{|l|}{ Variable } & \multirow{3}{*}{$\begin{array}{l}\text { Prevalence (\%) } \\
\text { OR } \\
3.5 \\
\end{array}$} & \multicolumn{3}{|c|}{ Univariable analysis } & \multicolumn{3}{|c|}{ Multivariable analysis } \\
\hline & & & $95 \% \mathrm{Cl}$ & $p$-value & AOR & $95 \% \mathrm{Cl}$ & $p$-value & \\
\hline \multirow{2}{*}{$\begin{array}{l}\text { Age } \\
(n=34,380)\end{array}$} & $\leq 25$ years $(n=27,337)$ & & \multicolumn{6}{|c|}{ Reference } \\
\hline & $>25$ years $(n=7,043)$ & 3.9 & 1.14 & $0.99-1.30$ & 0.063 & \multicolumn{3}{|c|}{ Not done } \\
\hline \multirow{2}{*}{$\begin{array}{l}\text { Sex } \\
(n=34,380)\end{array}$} & Male $(n=27,533)$ & 3.9 & \multicolumn{6}{|c|}{ Reference } \\
\hline & Female $(n=6847)$ & 2.2 & 0.56 & $0.47-0.66$ & $<0.001$ & 0.51 & $0.43-0.60$ & $<0.001$ \\
\hline \multirow{4}{*}{$\begin{array}{l}\text { Marital Status } \\
(\mathrm{n}=34,322)\end{array}$} & Single $(n=29,740)$ & 3.4 & \multicolumn{6}{|c|}{ Reference } \\
\hline & Married $(n=4,443)$ & 4.4 & 1.29 & $1.11-1.51$ & 0.001 & 1.14 & $0.92-1.41$ & 0.217 \\
\hline & Divorced $(n=109)$ & 4.6 & 1.35 & $0.55-3.32$ & 0.511 & 1.30 & $0.52-3.23$ & 0.579 \\
\hline & Widow/er $(n=30)$ & 0.1 & 3.12 & $0.95-10.32$ & 0,062 & 3.21 & $0.95-10.85$ & 0.060 \\
\hline \multirow{4}{*}{$\begin{array}{l}\text { Occupation } \\
(n=34,311)\end{array}$} & Student $(n=25,400)$ & 3.5 & \multicolumn{6}{|c|}{ Reference } \\
\hline & Employed $(n=4,231)$ & 3.2 & 0.93 & $0.77-1.11$ & 0.414 & 0.81 & $0.65-1.01$ & 0.064 \\
\hline & Self-Employed $(n=2,102)$ & 4.6 & 1.35 & $1.09-1.67$ & 0.006 & 1.10 & $0.86-1.40$ & 0.432 \\
\hline & Other $(n=2,578)$ & 4.5 & 1.33 & $1.09-1.62$ & 0.005 & 0.98 & $0.78-1.24$ & 0.880 \\
\hline \multirow{2}{*}{$\begin{array}{l}\text { Donation times } \\
(n=34,380)\end{array}$} & $\leq 1(n=15,526)$ & 5.1 & \multicolumn{6}{|c|}{ Reference } \\
\hline & $>1(n=18,854)$ & 2.3 & 0.44 & $0.39-0.49$ & $<0.001$ & 0.43 & $0.38-0.48$ & $<0.001$ \\
\hline
\end{tabular}

Table 4 Factors associated with hepatitis $\mathrm{C}$

\begin{tabular}{|c|c|c|c|c|c|c|c|c|}
\hline \multicolumn{2}{|l|}{ Variable } & \multirow{3}{*}{$\begin{array}{l}\text { Prevalence (\%) } \\
\text { OR } \\
1.2\end{array}$} & \multicolumn{3}{|c|}{ Univariable analysis } & \multicolumn{3}{|c|}{ Multivariable analysis } \\
\hline & & & $95 \% \mathrm{Cl}$ & $p$-value & $A O R$ & $95 \% \mathrm{Cl}$ & $p$-value & \\
\hline \multirow{2}{*}{$\begin{array}{l}\text { Age } \\
(n=34,380)\end{array}$} & $\leq 25$ years $(n=27,337)$ & & \multicolumn{6}{|l|}{ Reference } \\
\hline & $>25$ years $(n=7,043)$ & 0.5 & 0.47 & $0.33-0.66$ & $<0.001$ & 0.47 & $0.30-0.74$ & 0.001 \\
\hline \multirow[t]{2}{*}{ Sex $(n=34,380)$} & Male $(n=27,533)$ & 1.1 & \multicolumn{6}{|l|}{ Reference } \\
\hline & Female $(n=6847)$ & 0.7 & 0.65 & $0.48-0.88$ & 0.006 & 0.59 & $0.44-0.80$ & 0.001 \\
\hline \multirow{4}{*}{$\begin{array}{l}\text { Marital Status } \\
(n=34,322)\end{array}$} & Single $(n=29,740)$ & 1.1 & \multicolumn{6}{|c|}{ Reference } \\
\hline & Married $(n=4,443)$ & 0.8 & 0.77 & 0.54-1.08 & 0.130 & \multirow{3}{*}{\multicolumn{3}{|c|}{ Not done }} \\
\hline & Divorced $(n=109)$ & 0 & 1 & - & - & & & \\
\hline & Widow/er $(n=30)$ & 0 & 1 & - & - & & & \\
\hline \multirow{4}{*}{$\begin{array}{l}\text { Occupation } \\
(n=34,311)\end{array}$} & Student $(n=25,400)$ & 1.1 & \multicolumn{6}{|c|}{ Reference } \\
\hline & Employed $(n=4,231)$ & 0.7 & 0.61 & $0.41-0.89$ & 0.011 & 0.96 & $0.60-1.53$ & 0.859 \\
\hline & Self-Employed $(n=2,102)$ & 0.7 & 0.59 & $0.34-1.01$ & 0.055 & 0.83 & $0.46-1.48$ & 0.518 \\
\hline & Other $(n=2,578)$ & 0.9 & 0.76 & $0.49-1.17$ & 0.212 & 0.99 & $0.62-1.58$ & 0.959 \\
\hline \multirow{2}{*}{$\begin{array}{l}\text { Donation times } \\
(n=34,380)\end{array}$} & $\leq 1(n=15,526)$ & 1.2 & \multicolumn{6}{|c|}{ Reference } \\
\hline & $>1(n=18,854)$ & 0.9 & 0.78 & $0.63-0.96$ & $<0.019$ & 0.75 & $0.60-0.92$ & 0.007 \\
\hline
\end{tabular}

Table 5 Factors associated with syphilis

\begin{tabular}{|c|c|c|c|c|c|c|c|c|}
\hline \multicolumn{2}{|l|}{ Variable } & \multirow{3}{*}{$\begin{array}{l}\text { Prevalence (\%) } \\
\text { OR } \\
2.5\end{array}$} & \multicolumn{3}{|c|}{ Univariable analysis } & \multicolumn{3}{|c|}{ Multivariable analysis } \\
\hline & & & $95 \% \mathrm{Cl}$ & $p$-value & $A O R$ & $95 \% \mathrm{Cl}$ & $p$-value & \\
\hline \multirow{2}{*}{$\begin{array}{l}\text { Age } \\
(n=34,380)\end{array}$} & $\leq 25$ years $(n=27,337)$ & & \multicolumn{6}{|l|}{ Reference } \\
\hline & $>25$ years $(n=7,043)$ & 3.4 & 1.37 & $1.18-1.60$ & $<0.001$ & 1.04 & $0.82-1.33$ & 0.726 \\
\hline \multirow[t]{2}{*}{ Sex $(n=34,380)$} & Male $(n=27,533)$ & 2.9 & \multicolumn{6}{|l|}{ Reference } \\
\hline & Female $(n=6847)$ & 1.8 & 0.62 & $0.51-0.75$ & $<0.001$ & 0.61 & $0.50-0.74$ & $<0.001$ \\
\hline \multirow{4}{*}{$\begin{array}{l}\text { Marital Status } \\
(\mathrm{n}=34,322)\end{array}$} & Single $(n=29,740)$ & 2.4 & \multicolumn{6}{|l|}{ Reference } \\
\hline & Married $(n=4,443)$ & 4.2 & 1.76 & $1.49-2.07$ & $<0.001$ & 1.54 & 1.21-1.97 & 0.001 \\
\hline & Divorced $(n=109)$ & 3.7 & 1.53 & $0.56-4.17$ & 0.403 & 1.41 & $0.51-3.90$ & 0.509 \\
\hline & Widow/er $(n=30)$ & 0 & 1 & - & - & - & - & - \\
\hline \multirow{4}{*}{$\begin{array}{l}\text { Occupation } \\
(n=34,311)\end{array}$} & Student $(n=25,400)$ & 2.4 & \multicolumn{6}{|l|}{ Reference } \\
\hline & Employed $(n=4,231)$ & 2.5 & 1.04 & $0.84-1.28$ & 0.716 & 0.76 & $0.57-1.01$ & 0.058 \\
\hline & Self-Employed $(n=2,102)$ & 4.7 & 2.02 & $1.63-2.51$ & $<0.001$ & 1.44 & $1.09-1.90$ & 0.011 \\
\hline & Other $(n=2,578)$ & 3.6 & 1.51 & $1.21-1.89$ & $<0.001$ & 1.02 & $0.77-1.35$ & 0.891 \\
\hline \multirow{2}{*}{$\begin{array}{l}\text { Donation times } \\
(n=34,380)\end{array}$} & $\leq 1(n=15,526)$ & 3.3 & \multicolumn{6}{|l|}{ Reference } \\
\hline & $>1(n=18,854)$ & 2.1 & 0.62 & 0.54-0.71 & $<0.001$ & 0.63 & $0.55-0.72$ & $<0.001$ \\
\hline
\end{tabular}


first time blood donor, married and self-employed (Table 5).

\section{Discussions}

\section{Typical blood donor in Malawi}

The results of this study show that a typical voluntary nonremunerated blood donor (VNRBD) in Malawi is young, single, male and a student. The dominance of young unmarried males in the blood donor population is likely selfselection based on the population risk of HIV and explains the generally lower rate of prevalence in our study population compared to the national rates of $10.6 \%$ in 2010 and $10.4 \%$ in $2015^{15}$. At population level, HIV transmission in Malawi is mainly through stable heterosexual relationships. Prevalence is higher in those who have ever been married with rates of $3 \%$ for never been married, $9.8 \%$ for those currently married, $19.1 \%$ for those who are divorced or separated and $32.3 \%$ for those widowed ${ }^{15-16}$. At HIV prevalence of $6.4 \%$ for males aged $15-54$ years compared with $10.8 \%$ for females aged 15-49 years, males in Malawi have a lower prevalence of HIV than females ${ }^{15}$. This population level gender disparity in HIV prevalence is even more marked at a younger age: $1 \%$ for males against $4.9 \%$ for females aged $15-24$ years $^{15}$. However, in our study population, gender and marital status were not associated with a positive HIV result. This is probably because our study population was heavily skewed towards unmarried males. On the other hand, age above 25 years was associated with a higher HIV prevalence, a trend also observed in the general population ${ }^{15}$.

\section{Prevalence of transfusion transmissible infections}

During the period under study the prevalence of all transfusion transmissible infections (TTIs) showed a downward trend. The test kits and testing algorithm remained the same for all TTIs except for HIV whereby a supplementary rapid test kit had been added for all initial positives from August 2015.

This additional test meant that some of the initial positive reactions were found non-reactive and were thus labeled as discordant and classified as part of the missing data. However, discordant results for HIV in 2015 were only $0.6 \%$ with missing data for all years ranging from 2.3\% for 2011 to $17.5 \%$ for 2015 blood donors. This missing data was nondifferential and was also less than $20 \%$ for each year's data. In view of the short time from August to December 2015 when the HIV test algorithm was modified and the low level of missing data, it is suggestive that the general downward trend observed over this period is most likely a real observation. Additionally, the repeat blood donation rates over this period declined from $57.5 \%$ in 2011 to $51.0 \%$ in 2015 and the pattern of decline in TTI prevalence for all blood donors was similar to the pattern of decline in first time blood donors suggesting that this decline in prevalence was due to other factors and not an increase in the proportion of repeat blood donors or changes in laboratory screening methods.

While the blood donor HIV prevalence fell from 3.5\% in 2011 to $1.9 \%$ in 2015, the population level prevalence of HIV decreased only by $0.2 \%$ from $10.6 \%$ in 2010 to $10.4 \%$ in $2015^{15}$ which suggests that the decline in the prevalence of TTIs observed in this study was not due to a general decrease in the prevalence of T'TIs at population level. This decline was probably due to improved effectiveness of the blood donor education program in encouraging self-deferral amongst TTI positive individuals. This was also reflected in the prevalence for HIV of $1.9 \%$ in blood donors against the population prevalence of $10.4 \%$ in 2015 .
Nonetheless, the prevalence of TTIs in Malawian voluntary non-remunerated blood donors (VNRBDs) was quite high at $1.9 \%$ for HIV, $3.6 \%$ for HBV; $1.0 \%$ for HCV and $2.6 \%$ for syphilis when compared with other countries that collect blood from only VNRBDs where the prevalence is maintained at below 1\%. . $^{17-18}$

It must be stated that the prevalence for Malawian VNRBDs was based on unconfirmed screening test results because the MBTS was unable to confirm screen positives due to the high cost of confirmatory testing. Unconfirmed screening results tend to inflate the actual prevalence as it includes some false positives ${ }^{19}$. It is most likely that the actual prevalence of these TTIs was lower than what has been reported here. This therefore is one of the methodological weaknesses of this study.

The prevalence of HIV, HBV and HCV was consistently lower in VNRBDs when compared with reported prevalence in family replacement blood donors (FRBDs). The Ministry of Health quarterly HIV program reports showed an average prevalence of $6.3 \%$ for $\mathrm{HIV}, 5 \%$ for $\mathrm{HBV}, 1.7 \%$ for HCV and $2.6 \%$ for syphilis in FRBDs ${ }^{4-7}$. This is consistent with findings in other parts of Africa ${ }^{19-20}$. Allain (2010) argued that repeat blood donation was the main reason why VNRBDs are microbiologically safer than FRBDs and that first time VNRBDs have the same microbiological safety profile as FRBDs. He argued that studies that showed the higher microbiological safety of VNRBDs over FRBDs were confounded by age, sex and repeat blood donation and that there was no difference when like for like was compared ${ }^{20}$. The TTI prevalence among first time blood donors in this study indicates that FRBDs may have had similar HBV and lower syphilis prevalence than first time VNRBDs. However the HIV prevalence of $6.3 \%$ for FRBDs was 2.3 times that of first time VNRBDs. As the age and sex profile of the FRBDs in Malawi was not known further comparison was not possible and is recommended as a subject for future studies.

Repeat blood donors had a significantly lower prevalence for each TTI than first time blood donors.

This is because those found positive were not allowed to donate blood again. Nonetheless, the prevalence in this group was quite high at $1.2 \%$ for HIV, $2.3 \%$ for HBV, $0.9 \%$ for HCV and $2.1 \%$ for syphilis. This means that either the MBTS was allowing those who had previously tested positive to donate blood again or the false positive rates were high or the incidence of these diseases was high in the blood donor population. The latter has implications on the safety of the blood supply as these are candidates for donating while in the diagnostic window period thereby transmitting infections to blood recipients. It also has public health significance in that this newly infected population can remember events surrounding their infection and can provide insights into why and how new infections occur in an otherwise informed population. As such further analysis is needed to establish what is responsible for this high TTI prevalence in repeat blood donors.

\section{Test results for hepatitis $C$ virus}

Hepatitis C virus transmission is mainly through the parenteral route commonly via intravenous drug use, unsterile medical procedures and unsafe blood transfusions ${ }^{21-22}$. Lavanchy (2011), using data from an HCV prevalence study among Ghanaian children, extrapolated that HCV prevalence in 
Malawi was $6.8 \%$ in $2010^{21}$. The 2015 prevalence of HCV in Malawian VNRBDs was lower than this at $1 \%$ for all blood donors and slightly higher in first time blood donors at $1.2 \%$ against $0.9 \%$ in repeat blood donors. This difference in prevalence between first time and repeat blood donors was statistically significant ( $\mathrm{p}$-value $<0.001$ ). The prevalence reported in this study was based on unconfirmed screening test results as no confirmatory tests such as Nucleic Acid Testing or recombinant immunoblot assay (RIBA) were conducted. This methodological weakness of this study has already been stated earlier but is particularly significant for hepatitis $\mathrm{C}$ test results.

Studies conducted in Malawi which confirmed positive screening HCV results found very high false positive rates. ${ }^{8}$ ${ }^{23}$ Chasela et al (2012) found $98.1 \%$ false positive results among HIV positive pregnant women in Lilongwe ${ }^{23}$ while Candotti et al (2001) found 90\% false positive results among FRBDs in Ntcheu ${ }^{8}$. Other studies in other parts of the world also found high false positive rates and correlation with low signal to cut off (S/CO) ratios of less than 4.5. ${ }^{24-25}$ The $\mathrm{HCV}$ results in this study were based on the manufacturer's recommendation of labeling as positive all samples with an $\mathrm{S} / \mathrm{CO}$ ratio of $\geq 1$. HCV has not been described as a major problem in Malawi suggesting that it is a disease of low prevalence $^{26}$. The positive predictive value of a laboratory test tends to be lower when screening for infections in a population with low prevalence ${ }^{27}$. The low prevalence of $\mathrm{HCV}$, the $\mathrm{S} / \mathrm{CO}$ ratio used for determining a positive result and the high false positive rates described by other researchers in Malawi and in other parts of the world mean that the HCV prevalence described in this study must be used with caution.

\section{Hepatitis B virus and male blood donors}

Females had about half the HBV risk of males [OR 0.56 CI 0.47-0.66 adjusted OR 0.51, CI 0.43-0.60] which suggests that these viruses are associated with some male behavior. HBV transmission in endemic countries is thought to occur in early childhood predominantly through close personal contact with HBV-infected persons such as siblings or other children $^{28}$. If this was the main route of transmission in Malawian VNRBDs, the gender differences would not be there. The lack of association with age as is the case with HIV suggests that sexual transmission is not the main route of HBV transmission in Malawian blood donors.

We think that transmission could either be due to close shaves boys and men have in barbershops while girls and women go to salons or could be due to traditional male circumcision.

More studies are needed to determine the factors responsible for this gender disparity in $\mathrm{HBV}$ prevalence in Malawian VNRBDs.

\section{Conclusions}

The mean number of people donating blood at the MBTS was 39, 289 per year. The typical blood donor was a young unmarried male student. Hepatitis $\mathrm{B}$ had the highest prevalence in the blood donor population while hepatitis $\mathrm{C}$ had the lowest prevalence. The prevalence of all infections went down between 2011 and 2015. Repeat blood donation improves the microbiological safety of the blood supply. There is need for focused TTI prevention strategies in these young T'TI free blood donor populations to maintain a large pool of TTI negative regular blood donors.

\section{Acknowledgements}

We thank the Malawi Blood Transfusion Service for providing funding for this study.

\section{References}

1. World Health Organisation [Internet]. Geneva: Blood safety aidememoire for national health programmes; c2002 [Cited 2016 May 18]. Available from: http://www.who.int/bloodsafety/en/.

2. WHO (2002) Safe blood donation. Geneva .World Health Organization.:

3. National Statistical Office (2001). Malawi Demographic and Health Survey 2000. Malawi. National Statistical Office.

4. Ministry of Health (2015). Integrated HIV program report January -March 2015. Lilongwe. Ministry of Health.

5. Ministry of Health (2015). Integrated HIV program report April -June 2015.Lilongwe. Ministry of Health.

6. Ministry of Health (2015). Integrated HIV program report July -September 2015.Lilongwe. Ministry of Health.

7. Ministry of Health (2015). Integrated HIV program report October -December 2015.Lilongwe. Ministry of Health.

8. Candotti D, Mundy C, Kadewele G, Nkhoma W, Bates I, Allain JP. Serological and molecular screening for viruses in blood donors from Ntcheu, Malawi: high prevalence of HIV-1 subtype C and of markers of hepatitis B and C viruses. J Med Virol. 2001 Sep;65(1):1-5 .

9. Chinkhumba J. Economics of blood screening: in search of an optimal blood screening strategy. Trop Doc. 2006 Jan; 36(1):32-4. doi: $10.1258 / 004947506775598815$.

10. Maida MJ, Daly CC, Hoffman I, Cohen MS, Kumwenda M, Vernazza PL. Prevalence of hepatitis C infection in Malawi and lack of association with sexually transmitted diseases. Eur J Epidemiol. 2000; 16(12):1183-4. .

11. World Health Organization (2010). Towards 100\% voluntary blood donation: a global framework for action. Geneva .World Health Organization.

12. Tessema B, Yismaw G, Kassu A, Amsalu A, Mulu A, Emmrich F, et al. Seroprevalence of HIV, HBV, HCV and syphilis infections among blood donors at Gondar University Teaching Hospital, Northwest Ethiopia: declining trends over a period of five years. BMC Infect Dis. 2010 May 10; 10:111. doi: 10.1186/1471-2334-10-11

13. Xie DD, Li J, Chen JT, Eyi UM, Matesa RA, Obono MM, et al. Seroprevalence of human immunodeficiency virus, hepatitis B virus, hepatitis $\mathrm{C}$ virus, and Treponema pallidum infections among blood donors on Bioko Island, Equatorial Guinea. PLoS One. 2015 Oct 8;10(10):e0139947. doi: 10.1371/journal.pone.0139947. eCollection 2015

14. Club25pledge.org. [Internet]. c2014 [Cited May 2016]. Available from: http://www.club25pledge.org/.

15. National Statistical Office (NSO) [Malawi] and ICF. 2017. Malawi Demographic and Health Survey 2015-16. Zomba, Malawi, and Rockville, Maryland, USA. NSO and ICF.

16. National AIDS Commission (2014). 2015-2020 National strategic plan for HIV and AIDS. Lilongwe.

17. South African National Blood Service. Integrated Annual Report 2016. Johannesburg; South African National Blood Service; 2016

18. Glynn SA, Kleinman SH, Schreiber GB, Busch MP, Wright DJ, Smith JW, et al. Trends in incidence and prevalence of major transfusiontransmissible viral infections in US blood donors, 1991 to 1996. JAMA. 2000 Jul 12; 284(2):229-35..

19. Allain JP. Moving on from voluntary non-remunerated donors: who is the best blood donor? Br J Haematol. 2011 Sep; 154(6):763-9. doi: 
10.1111/j.1365-2141.2011.08708.x. Epub 2011 May 3. Review. .

20. Allain JP. Volunteer safer than replacement donor blood: a myth revealed by evidence. ISBT Science Series. 2010 Jul 1; 5(n1):169-75. doi: 10.1111/j.1751-2824.2010.01423.x.

21. Lavanchy D. Evolving epidemiology of hepatitis C virus. Clin Microbial Infect. 2011 Feb; 17(2):107-15. doi: 10.1111/j.14690691.2010.03432.x. Review. .

22. Sievert W, Altraif I, Razavi HA, Abdo A, Ahmed EA, AlOmair A, et al. A systematic review of hepatitis $C$ virus epidemiology in Asia, Australia and Egypt. Liver Int. 2011 Jul; 31 Suppl 2:61-80. doi: 10.1111/j.1478-3231.2011.02540.x. Review.

23. Chasela CS, Wall P, Drobeniuc J, King CC, Teshale E, Hosseinipour $\mathrm{MC}$, et al. Prevalence of hepatitis $\mathrm{C}$ virus infection among human immunodeficiency virus-1-infected pregnant women in Malawi: the BAN study. J Clin Virol. 2012 Aug; 54(4):318-20. doi: 10.1016/j. jcv.2012.05.003. Epub 2012 Jun 2. .

24. Contreras AM, Tornero-Romo CM, Toribio JG, Celis A, OrozcoHernández A, Rivera PK, et al. Very low hepatitis C antibody levels predict false-positive results and avoid supplemental testing. Transfusion. 2008 Dec; 48(12):2540-8. doi: 10.1111/j.15372995.2008.01886.x. Epub 2008 Aug 1.

25. Ren FR, Lv QS, Zhuang H, Li JJ, Gong XY, Gao GJ, et al. Significance of the signal-to-cutoff ratios of anti-hepatitis $\mathrm{C}$ virus enzyme immunoassays in screening of Chinese blood donors. Transfusion. 2005 Nov; 45(11):1816-22. Erratum in: Transfusion. 2006 Jan; 46(1): 163 .

26. Ministry of Health (2011). Malawi Health Sector Strategic Plan 2011-2016: Moving towards equity and quality. Lilongwe.

27. Grimes DA, Schulz KF. Uses and abuses of screening tests. Lancet. 2002 Mar 9; 359(9309):881-4. Review. Erratum in: Lancet. 2008 Jun 14; 371(9629):199.

28. McMahon BJ. Epidemiology and natural history of hepatitis B. Semin Liver Dis. 2005; 25 Suppl 1:3-8. Review.

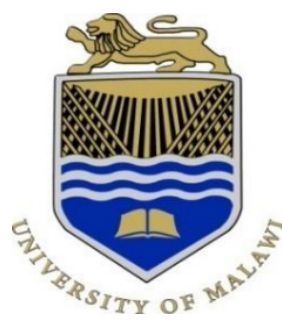

College of Medicine

WRITING WINNING PROPOSALS COURSE

\section{Facilitation: Research Support Centre}

Dates: 27-28 June 2019

\section{Venue: College of Medicine, Research Support Centre Conference Room}

The course is offered by Research Support Centre (RSC), a centre with renowned history of delivering high quality training courses and services in writing winning proposals. RSC's courses are delivered by highly qualified facilitators, guaranteeing the trainees of invaluable training standards.

Target Audience: Investigators, young researchers, postgraduate fellows and all interested.

About the course: The following modules shall be delivered

\section{Understand the proposal writing process}

\section{Develop different kinds of proposals}

\section{Target their proposals for an appropriate audience}

Identify potential funders for different ideas

\section{Perform needs analysis that will enable development of a feasible proposal}

\section{Format their proposal professionally}

Construct words, sentences and paragraphs professionally

Course Fee \$200 per participant: Course fee covers course material, lunch and refreshments

Application deadline: Applications should be submitted to info@medcol.mw (with a copy to rscinformationunit@gmail.com) no later than Tuesday the 25th of June, 2019.

If you need more information, send an email to info@medcol.mw (with a copy to rscinformationunit@gmail.com). 